\title{
A probabilistic Meir-Keeler type fixed point theorem which characterizes metric completeness
}

\author{
RAVINDRA K. BISHT
}

\begin{abstract}
.
A probabilistic version of the Meir-Keeler type fixed point theorem, which characterizes completeness of the metric space is established. In addition to it, a fixed point theorem for non-expansive mappings satisfying $(\epsilon-\delta)$ type condition in Menger probabilistic metric space (Menger PM-space) is proved. As a byproduct we find an affirmative answer to the open question on the existence of contractive mappings which admit discontinuity at the fixed point (see Rhoades, B. E., Contractive definitions and continuity, Contemporary Mathematics 72 (1988), 233-245, p. 242) in the setting of Menger PM-space.
\end{abstract}

Acknowledgment. The author is thankful to the referees for their valuable suggestions for the improvement of the paper.

\section{REFERENCES}

[1] Abtahi, M., Suzuki-type fixed point theorems for generalized contractive mappings that characterize metric completeness, Bull. Iranian Math. Soc., 41 (2015), No. 4, 931-943

[2] Berinde, V. and Choban, M., Remarks on some completeness conditions involved in several common fixed point theorems, Creat. Math. Inform., 19 (2010), No. 1, 1-10

[3] Bisht, R. K. and Pant, R. P., A remark on discontinuity at fixed point, J. Math. Anal. Appl., 445 (2017), 1239-1242

[4] Bisht, R. K. and Rakočević, V., Generalized Meir-Keeler type contractions and discontinuity at fixed point, Fixed Point Theory, 19 (2018), No. 1, 57-64

[5] Ćirić, Lj. B, On contraction type mappings, Math. Balkanica, 1 (1971), 52-57

[6] Hicks, T. and Rhoades, B. E., Fixed points and continuity for multivalued mappings, International J. Math. Math. Sci., 15 (1992), 15-30

[7] Hicks, T. L. and Rhoades, B. E., A Banach type fixed-point theorem, Math. Japon., 24 (1979/80), 327-330

[8] Kadelburg, Z., Radenović, S. and Shukla, S., Boyd-Wong and Meir-Keeler type theorems in generalized metric spaces, J. Adv. Math. Stud., 9 (2016), No. 1, 83-93

[9] Meir, A. and Keeler, E., A theorem on contraction mappings, J. Math. Anal. Appl., 28 (1969), 326-329

[10] Menger, K., Statistical metric, Proc. Nat. Acad. Sci. USA, 28 (1942), 535-537

[11] Mitrović, Z. and Radenović, S., On Meir-Keeler contraction in Branciari b-metric spaces, Transactions of A. Razmadze Mathematical Institute, 173 (2019), 83-90

[12] Nguyen, L. V., On fixed points of asymptotically regular mappings, Rend. Circ. Mat. Palermo, II. Ser (to appear)

[13] Pant, A. and Pant, R. P., Fixed points and continuity of contractive maps, Filomat 31 (2017),No. 11, 3501-3506

[14] Pant, A., Pant, R. P. and Joshi, M. C., Caristi type and Meir-Keeler type fixed point theorems, Filomat, 33 (2019), No. 12, 3711-3721

[15] Pant, R. P., Discontinuity and fixed points, J. Math. Anal. Appl., 240 (1999), 284-289

[16] Pant, R. P., Özgür, N. Y. and Taş, N., On discontinuity problem at fixed point, Bull. Malays. Math. Sci. Soc., 43 (2020), No. 1, 499-517

[17] Pant, R. P., Pant, A., Nikolić, R. M. and Ješić, S. N., A characterization of completeness of Menger PM-spaces, J. Fixed Point Theory Appl., 21, (2019), 90 pp.

Received: 29.04.2020; In revised form: 10.06.2020; Accepted: 11.06.2020

2010 Mathematics Subject Classification. 47H10, 54E50.

Key words and phrases. Menger PM-spaces, fixed point, lower semicontinuity, nonexpansive mapping. 
[18] Pant, R. P., Özgür N. Y. and Taş, N., Discontinuity at fixed points with applications, Bulletin of the Belgian Mathematical Society-Simon Stevin, 25 (4), (2019), 571-589

[19] Popescu, O., A new type of contractions that characterize metric completeness, Carpathian J. Math., 31 (2015), No. 3, 381-387

[20] Rhoades, B. E, Contractive definitions and continuity, Contemporary Mathematics, 72 (1988), 233-245

[21] Schweizer, B. and Sklar, A., Statistical metric spaces, Pacific J. Math., 10 (1960), 415-417

[22] Schweizer, B. and Sklar, A., Probabilistic Metric Spaces, North-Holland, New York, Elsevier 1983

[23] Sehgal, V. M. and Bharucha-Reid, A. T., Fixed points of contraction mappings in PM-spaces, Math. System Theory, 6 (1972), 97-102

[24] Subrahmanyam, P. V., Completeness and fixed points, Monatsh. Math., 80 (1975), 325-330

[25] Suzuki, T., A generalized Banach contraction principle that characterizes metric completeness, Proc. Amer. Math. Soc., 136 (2008), No. 5, 1861-1869

[26] Taş, N. and Özgür, N. Y., A new contribution to discontinuity at fixed point, Fixed Point Theory, 20 (2019), No. $2,715-728$

[27] Todorčević, V., Harmonic Quasiconformal Mappings and Hyperbolic Type Metric, Springer Nature Switzerland AG 2019

\section{DEPARTMENT OF MATHEMATiCS}

NATional Defence ACADEMY

KHADAKWASLA-411023, PUNE, INDIA

Email address: ravindra.bisht @yahoo.com 